\title{
Contactless approach to determine pavement skid resistance for Pavement Management System
}

\author{
Jakub Fengier ${ }^{1, *}$, Mieczysław Słowik ${ }^{1}$, and Andrzej Pożarycki ${ }^{1}$ \\ ${ }^{1}$ Poznan University of Technology, Institute of Civil Engineering, Piotrowo 5, 60-965 Poznań, Poland \\ Keywords: Pavement Management System, skid resistance, pavement surface
}

\begin{abstract}
Standard method to assess the pavement profile is to calculate the MPD (Mean Profile Depth) index based on results obtained usually by usage of laser techniques. In analysis the models of the surface pavements have been used in order to calculate the $\mathrm{s}_{1}, \mathrm{~s}_{2}, \mathrm{~s}_{3}$ parameters values corresponding to mega-, macro- and microtexture respectively. The values of the developed parameters $\mathrm{s}_{1}, \mathrm{~s}_{2}, \mathrm{~s}_{3}$ are calculated from the specific power spectral density values of surface roughness obtained for the threshold pavement roughness wavelength equal to $0.1,0.05,0.005$ and $0.0005 \mathrm{~m}$. The skid resistance has been correlated to the $\mathrm{s}_{1}, \mathrm{~s}_{2}, \mathrm{~s}_{3}$ parameters using 11 varied cases related to asphalt and concrete pavements. Skid resistance tests have been performed using CSR (Continuous Skid Resistance) device with fixed slip ratio equal to $13 \%$. Three different test speed values 45,65 and $95 \mathrm{~km} / \mathrm{h}$ have been used. The obtained results lead to factorial correlation equations between developed parameters and skid resistance indices. Correlation results for uncontaminated pavement surface can be characterized by the coefficient of determination values in range between 0.55 and 0.94 . The results can be used for contactless determination of pavement skid resistance in Pavement Management System.
\end{abstract}

\section{Introduction}

Road pavement diagnosis is a part of Pavement Management System (PMS). To manage the road network there is need to assess each parameter in reliable and effective way. In this paper there has been performed an attempt to evaluate skid resistance by using the model of pavement surface roughness. Laser based parameters are widely used to assess the pavement surface profile. Examples of the measurement methods are LTS [1], CTMeter [2] or SUPPORT system [3]. Other method is to measure force needed to drag the rubber elements on the pavement surface. In this case DFT [2] and British Pendulum Tester [4] should be mentioned. Results of measurement consisting of both methods have been correlated with (commonly used on Polish national roads) skid resistance tester - SRT [5].

\footnotetext{
*Corresponding author: jakub.fengier@put.poznan.pl
} 
Another step is to evaluate the pavement surface. The first attempt was based on laser method to obtain the shape of surface of the pavement [6]. Photogrammetric method is a relatively new idea to assess the surface of the pavement. This method is based on the few high resolution photos of the same pavement area from different perspectives. The solution is shown in papers [7], [8] and first Polish approach is described in paper [9].

Pavement skid resistance research is not limited to looking for the highly correlated friction coefficients with pavement surface parameters, but also there are first attempts to solve this issue in an analytical way. Among the most relevant approaches is the paper [10] where author formed the equation between friction coefficient and surfaces roughness of pavement and tire. Another attempt worth mentioning is empirical attempt to use that equation in road pavement measurements $[11,12]$. Other approach is described in paper [13] where author assumes that skid resistance mostly depends on upper part of pavement surface.

The attempt of correlation between parameters based on pavement surface and skid resistance index is shown in this paper.

\section{Methods}

\subsection{Skid resistance test}

Skid resistance was tested using CSR (Continuous Skid Resistance) device shown in fig. 1. CSR is a device that allows to extract from the measurements the both vertical force values taking effect on measurement wheel and torque values. The slip ratio used in the device is equal to $13 \%$.

The skid resistance index based on CSR device is determined by the formula 1 :

Equations should be centred and should be numbered with the number on the right-hand side.

$$
\mathrm{CSRi}=\mathrm{M} /(\mathrm{F} \cdot \mathrm{r})
$$

where: $\mathrm{M}$ - torque values measured by using the moment transducer [Nm]

$\mathrm{F}-$ vertical force $[\mathrm{N}]$

$\mathrm{r}$ - distance between pavement surface and axis of the measuring wheel [m].

More details about CSR device provided in paper [9]

\subsection{Parameters based on pavement surface model}

Parameters called $s_{1}, s_{2}$ and $s_{3}$ have been introduced to enable the classification of the roughness of the pavement surface in general. Most commonly used classification of the roughness of the pavement surface includes [14]:

-microtexture (wavelength lesser than $0.5 \mathrm{~mm}$ and amplitude lesser than $0.2 \mathrm{~mm}$ )

-macrotexture (wavelength between 0.5 and $50 \mathrm{~mm}$, amplitude between 0.1 and $20 \mathrm{~mm}$ )

-megatexture (wavelength between than 50 and $500 \mathrm{~mm}$, amplitude between 0.1 and 50 $\mathrm{mm})$

All three parameters affect on skid resistance; that is the reason to perform model consisting of all three of them. 
Calculation of the $s_{1}, s_{2}, s_{3}$ parameters is a process which contains the following steps: 1) taking the high resolution photos using the method described in [9], 2) developing the model of the pavement surface (calculation of co-ordinates of points forming the discrete surface) [9], 3) calculation of power spectral density for 2D model of achieved surface, 4) determine the value of power spectral density for specific wavelengths and 5) calculating the values of $\mathrm{s}_{1}, \mathrm{~s}_{2}, \mathrm{~s}_{3}$ parameters.

Calculation of the power spectral density surface roughness was based on the co-ordinates obtained from photogrammetric analysis by using the following equation, adopted after [15].

where:

$$
\mathrm{Cq}=(\Delta \mathrm{x} \cdot \Delta \mathrm{y}) /\left(\mathrm{m} \cdot \mathrm{n}[2 \pi]^{2}\right) \cdot\left|\mathrm{FFT}^{2 \mathrm{D}}\right|^{2}
$$

$\mathrm{Cq}$ is the two-dimensional surface roughness power spectrum. Cq values calculated in two directions are determined in wavenumber domain. Cq consist of values corresponding to each wavenumber of surface roughness present on the observed area; $\Delta \mathrm{x}$ and $\Delta \mathrm{y}$ are the lateral resolution of co-ordinates of model of the pavement within a grid of $m \times n$ data points in the $\mathrm{x}$ - and $\mathrm{y}$-directions, respectively; $\left|\mathrm{FFT}^{2 \mathrm{D}}\right|-$ absolute value from $2 \mathrm{D}$ Fast Fourier Transform,

From calculated $\mathrm{Cq}$ values corresponding to the wavelengths of the pavement roughness: $0.0005 \mathrm{~m}, 0.005 \mathrm{~m}, 0.05$ and $0.1 \mathrm{~m}$ which are related to wavenumbers $2000 \mathrm{~m}^{-1}, 200 \mathrm{~m}^{-1}, 20$ $\mathrm{m}^{-1}$ and $10 \mathrm{~m}^{-1}$, respectively. Parameters $\mathrm{s}_{1}, \mathrm{~s}_{2}$ and $\mathrm{s}_{3}$ have been calculated from following equation:

$$
\mathrm{s}_{\mathrm{i}}=(\mathrm{Cq}(\mathrm{a})-\mathrm{Cq}(\mathrm{b})) /(\mathrm{a}-\mathrm{b})
$$

where: $a$ and $b$ is wave number (for $\mathrm{s}_{1} \mathrm{a}=20 \mathrm{~m}^{-1}, \mathrm{~b}=10 \mathrm{~m}^{-1}$ for $\mathrm{s}_{2} \mathrm{a}=200 \mathrm{~m}^{-1}, \mathrm{~b}=20 \mathrm{~m}^{-1}$ for $\mathrm{s}_{3}$ $a=2000 \mathrm{~m}^{-1}, \mathrm{~b}=200 \mathrm{~m}^{-1}$ )

\section{Experimental program}

In order to create a pavement surface model and determine skid resistance from its features, the pavement skid resistance and surface roughness tests have been made. The test sections derived from both asphalt pavements (uncontaminated and contaminated) and concrete pavement (with and without marking). For evaluate the pavements surfaces, several photogrammetric points have been performed on each section. The test has been performed on road and airport pavements. The extracted test sections of $100 \mathrm{~m}$ length were considered. As far as the CSR device is a continues-like measurement device, the CSRi values have been reported for every subsection. In every section several repetitions have been performed (due to state of the section and availability).The skid resistance tests have been performed using three test velocities $45,65,95 \mathrm{~km} / \mathrm{h}$. In this paper each section has been marked as:

- nov (section localized on taxiway named November). SMA wearing course was paved 2 weeks before tests, 6 repetitions have been performed.

- $\quad$ h4 (section localized on taxiway named Hotel 4). SMA wearing course was paved 2 weeks before tests, 10 repetitions have been performed.

- $\quad$ h5 (section localized on taxiway named Hotel 5), SMA wearing course was paved 2 weeks before tests, 10 repetitions have been performed.

- RWc (section localized on runway pavement without contaminations). Concrete surface course was paved 2 years before tests. Aggregate used in concrete was granite crushed stone $0 / 22$. Thickness of the concrete layer was $30 \mathrm{~cm}$, concrete class was C35/45 and exposure class was XF4. Brushing process was used to texture the surface of the layer. 
Few weeks before tests the hydrophobization process was done. 6 repetitions have been preformed.

- RWr section localized on runway contaminated by rubber, 6 repetitions have been performed.

- RWm section localized on runway with marking, 6 repetitions have been performed.

- $\quad$ E (section localized on Echo 1 taxiway), cracked concrete wearing course with 0/22 aggregate. This taxiway is planned to be repaired due to its technical condition, 3 repetitions have been performed.

- Gc (section localized on taxiway excluded from traffic), concrete wearing course paved decades before tests, 3 repetitions have been performed.

- $\mathrm{Gm}$ (section localized on taxiway excluded from traffic with freshly made marking), concrete wearing course paved decades before tests, 3 repetitions have been performed.

- $\quad$ pc section on selected street in Poznan. Asphalt wearing course was paved 2 years before tests (test section after cleaning process), 3 repetitions have been performed.

- $\quad \mathrm{pb}$ section on street mentioned above. Asphalt wearing course was paved 2 years before tests (test section before cleaning process, contaminated with mineral contamination from nearby parking entrance with ground pavement), 3 repetitions have been performed.

Number of each cases was 109 and after using the statistical Grubb's test [16] used to detect outliers to further analysis 96 cases were taken into account. The same result has been obtained using 3 sigma rule [16].

\section{Analysis of the results}

The results of $s_{1}, s_{2}$ and $s_{3}$ parameter obtained on each section in function of CSRi calculated for that section has been shown in figure 1 .

Three types of regression equation were used in order to determine the relation between $\mathrm{s}_{1}$, $\mathrm{s}_{2}$ and $\mathrm{s}_{3}$ values and the skid resistance index CSRi:

Linear equation

$$
\operatorname{CSRi}(v)={ }^{w}+a_{1} s_{1}+a_{2} s_{2}+a_{3} s_{3}
$$

Factorial equation

$$
\operatorname{CSRi}(v)=w+b_{1} s_{1}+b_{2} s_{2}+b_{3} s_{3}+b_{4} s_{1} s_{2}+b_{5} s_{1} s_{3}+b_{6} s_{2} s_{3}+b_{7} s_{1} s_{2} s_{3}
$$

2nd degree polynomial (quadratic) equation

$$
\operatorname{CSRi}(\mathrm{v})={ }_{\mathrm{w}}+\mathrm{c}_{1} \mathrm{~s}_{1}+\mathrm{c}_{2} \mathrm{~s}_{1}{ }^{2}+\mathrm{c}_{3} \mathrm{~s}_{2}+\mathrm{c}_{4} \mathrm{~s}_{2}{ }^{2}+\mathrm{c}_{5} \mathrm{~s}_{3}+\mathrm{c}_{6} \mathrm{~s}_{3}{ }^{2}
$$

Where: $\mathrm{w}$ - CSRi intercept

$\mathrm{a}_{\mathrm{i}} / \mathrm{b}_{\mathrm{i}} / \mathrm{c}_{\mathrm{i}}-$ regression coefficients

$\mathrm{v}-$ test velocity

\section{Discussion}

Modeling the skid resistance of concrete and asphalt pavements without contamination using $s_{1}, s_{2}$ and $s_{3}$ parameters allows to achieve the coefficient of determination values $r^{2}$ 0.85 to 0.90 and 0.55 to 0.70 , respectively. The largest values of $r^{2}$ were obtained when one used the factorial equation. It was found that they need the largest number of regression coefficients to be determined. According to the generally accepted trend, the CSRi intercept 
in this model decreases when the test speed increases. There were no unambiguous rends for the other values of this model along with the increase of the test speed.

The residual values analysis leads to the assumption that following factorial equations $(7,8$, $9,10,11,12)$ are characterized by distribution of residual values similar to normal distribution. A part of other equations residual values distribution differ significantly from normal distribution. Some of the variables were statistically insignificant due to $\alpha=0.05$, presented equations have all factors including statistically insignificant. No tendency of particular variable has been noticed due to statistical significance.

When combining datasets from asphalt and concrete pavements without contamination regression equations lead to decrease (comparing to results from separated datasets) coefficient of determination $\mathrm{r}^{2}$ from 0.02 to 0.15 .

The combination of datasets for modeling on concrete surfaces with rubber contamination and marking levels lead to reducing the $r^{2}$ to range of values between 0.04 and 0.30 .

However, the photogrammetric methods lead to successful determination of the pavement skid resistance and the most successful models are shown (equations 7-12):

for asphalt pavements without contaminations:

$\mathrm{CSRi}=0.61-3.62 \mathrm{E} 15 \cdot \mathrm{s}_{1}-4.46 \mathrm{E} 16 \cdot \mathrm{s}_{2}-3.13 \mathrm{E} 20 \cdot \mathrm{s}_{3}+3.24 \mathrm{E} 33 \cdot \mathrm{s}_{1} \cdot \mathrm{s}_{2}+5.65 \mathrm{E} 33 \cdot \mathrm{s}_{1} \cdot \mathrm{s}_{3}+2.76 \mathrm{E} 38 \cdot \mathrm{s}_{2} \cdot \mathrm{s}_{3}-$

$$
\mathrm{v}=45 \mathrm{~km} / \mathrm{h} ; \mathrm{r}^{2}=0.55
$$

$\mathrm{CSRi}=0.58-4.22 \mathrm{E} 15 \cdot \mathrm{s}_{1}+1.43 \mathrm{E} 16 \cdot \mathrm{s}_{2}-3.73 \mathrm{E} 20 \cdot \mathrm{s}_{3}+2.90 \mathrm{E} 33 \cdot \mathrm{s}_{1} \cdot \mathrm{s}_{2}+6.86 \mathrm{E} 36 \cdot \mathrm{s}_{1} \cdot \mathrm{s}_{3}+2.72 \mathrm{E} 38 \cdot \mathrm{s}_{2} \cdot \mathrm{s}_{3}-$

$\mathrm{v}=65 \mathrm{~km} / \mathrm{h} ; \mathrm{r}^{2}=0.60$

$\mathrm{CSRi}=0.57-3.57 \mathrm{E} 15 \cdot \mathrm{s}_{1}+1.34 \mathrm{E} 16 \cdot \mathrm{s}_{2}-3.67 \mathrm{E} 20 \cdot \mathrm{s}_{3}+4.37 \mathrm{E} 33 \cdot \mathrm{s}_{1} \cdot \mathrm{s}_{2}+6.28 \mathrm{E} 36 \cdot \mathrm{s}_{1} \cdot \mathrm{s}_{3}+3.63 \mathrm{E} 38 \cdot \mathrm{s}_{2} \cdot \mathrm{s}_{3}-$

$$
\mathrm{v}=95 \mathrm{~km} / \mathrm{h} ; \mathrm{r}^{2}=0.70
$$

for concrete pavements without contaminations:

$$
\begin{gathered}
\mathrm{CSRi}=0.75-2.42 \mathrm{E} 17 \cdot \mathrm{s}_{1}-1.30 \mathrm{E} 19 \cdot \mathrm{s}_{2}-3.72 \mathrm{E} 20 \cdot \mathrm{s}_{3}+9.25 \mathrm{E} 36 \cdot \mathrm{s}_{1} \cdot \mathrm{s}_{2}+3.11 \mathrm{E} 38 \cdot \mathrm{s}_{1} \cdot \mathrm{s}_{3}+5.51 \mathrm{E} 40 \cdot \mathrm{s}_{2} \cdot \mathrm{s}_{3}- \\
3.37 \mathrm{E} 58 \cdot \mathrm{s}_{1} \cdot \mathrm{s}_{2} \cdot \mathrm{s}_{3}(10) \\
\mathrm{v}=45 \mathrm{~km} / \mathrm{h} ; \mathrm{r}^{2}=0.94 \\
\mathrm{CSRi}=0,73-3.00 \mathrm{E} 17 \cdot \mathrm{s}_{1}-1,23 \mathrm{E} 19 \cdot \mathrm{s}_{2}-2.71 \mathrm{E} 21 \cdot \mathrm{s}_{3}+9.64 \mathrm{E} 36 \cdot \mathrm{s}_{1} \cdot \mathrm{s}_{2}+2.28 \mathrm{E} 39 \mathrm{~s}_{1} \mathrm{~s}_{3}+7.99 \mathrm{E} 40 \mathrm{~s}_{2} \mathrm{~s}_{3}- \\
5.98 \mathrm{E} 58 \cdot \mathrm{s}_{1} \cdot \mathrm{s}_{2} \cdot \mathrm{s}_{3}(11) \\
\mathrm{v}=65 \mathrm{~km} / \mathrm{h} ; \mathrm{r}^{2}=0.88 \\
\mathrm{CSRi}=0.74-2.81 \mathrm{E} 17 \cdot \mathrm{s}_{1}-1.17 \mathrm{E} 19 \cdot \mathrm{s}_{2}-3.35 \mathrm{E} 21 \cdot \mathrm{s}_{3}+9.25 \mathrm{E} 36 \cdot \mathrm{s}_{1} \cdot \mathrm{s}_{2}+2.23 \mathrm{E} 39 \cdot \mathrm{s}_{1} \cdot \mathrm{s}_{3}+8.19 \mathrm{E} 40 \mathrm{~s}_{2} \mathrm{~s}_{3}- \\
\mathrm{v}=95 \mathrm{~km} / \mathrm{h} ; \mathrm{r}^{2}=0.85
\end{gathered}
$$



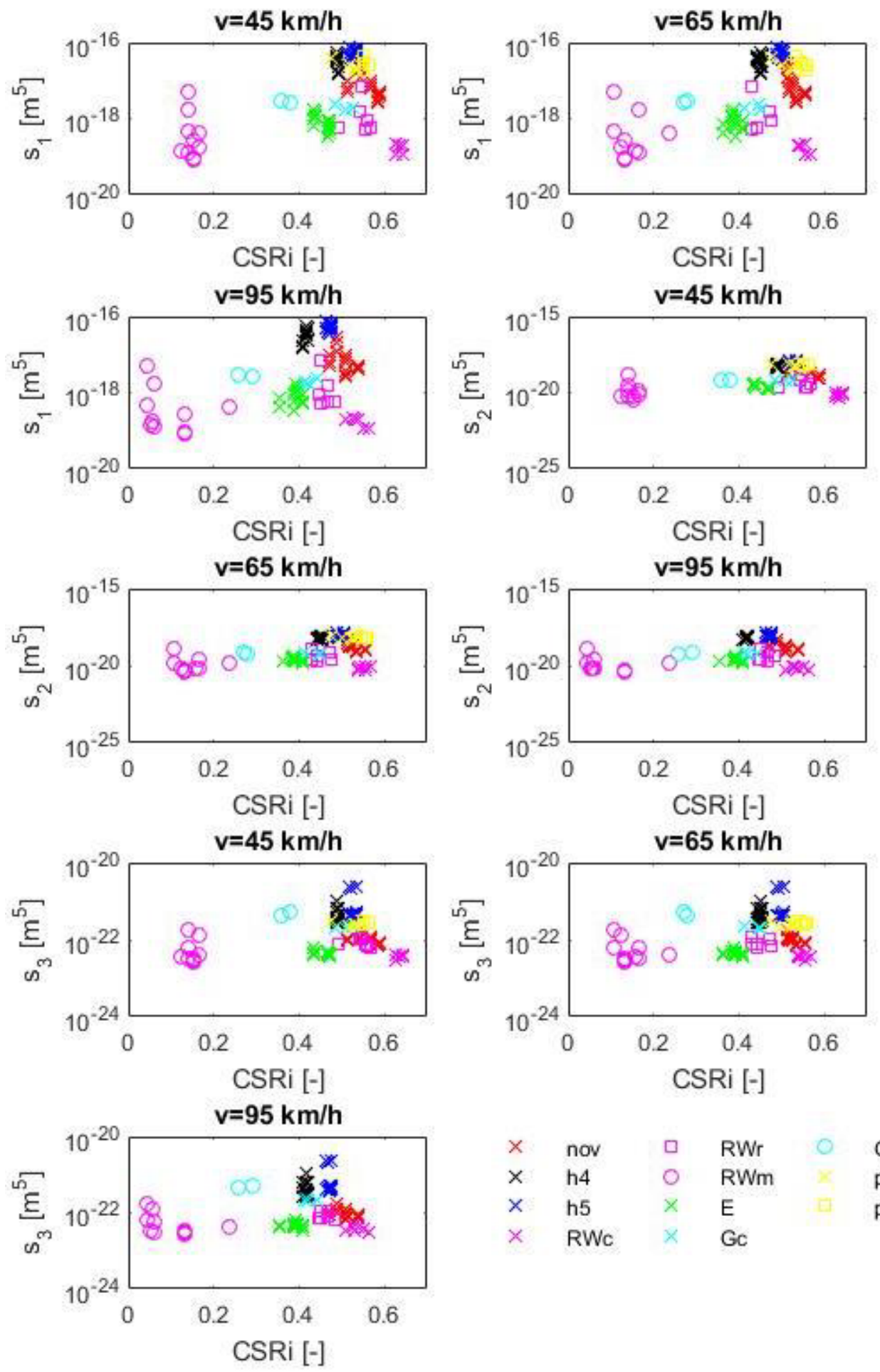

$\begin{array}{lllll}\times & \text { nov } & \square & \text { RWr } & \text { Gm } \\ \times & \text { h4 } & 0 & \text { RWm } & \text { pc } \\ \times & \text { h5 } & \times & \text { E } & \text { pb } \\ \times & \text { RWc } & \times & \text { Gc } & \end{array}$

Fig. 1 Results of calculated s1, s2 and s3 parameters in CSRi function for different test velocity 
Datasets including contaminated and uncontaminated pavement surfaces require to use two different approaches. The most successful models are related to uncontaminated pavements. No unambiguous relation between $\mathrm{s}_{1}, \mathrm{~s}_{2}, \mathrm{~s}_{3}$ and CSRi(v) can be performed using linear equations. None of the considered parameters affect significantly skid resistance on its own.

\section{Conclusions}

Based on the results of the skid resistance tests and pavement roughness obtained from photogrammetric method the relationship between these values was specified. Three different types of equations were used in order to calculate skid resistance index from values based on the power spectral density of pavement roughness.

Taking into account the contaminated pavement surfaces, significant different regression equations were discovered. In general, the coefficient of determination values are lower for results obtained from the measurements made on contaminated pavements comparing to values achieved from equations based on results obtained on uncontaminated pavement surfaces. However, the most successful models are related to measurements made on pavements without contaminations.

In order to estimate more reliable function describing skid resistance parameters there is a possibility to specify macrotexture by MTD (stand for texture depth) and MPD (stand for profile depth) and microtexture corresponding to BPT (British Portable Tester). Consideration of those parameters and proposed testing method of determination $s_{1}, s_{2}, s_{3}$ can lead to reliable model used to calculate skid resistance parameters in contactless way. Further studies can lead to the tool which can be use in Pavement Management System.

\section{References}

1 P. Vecura, L. Lane, D. Cheng, Caltrans Using Fog and Rejuvenating Seals on State Highways for Preventative Maintenance, (2013)

2 M. Jackson, Harmonization of Texture and Skid-Resistance Measurement Florida Department of Transportation, (2008)

3 I. Wyczałek, J. Stróżyk-Weiss, M. Wyczałek, Archives of Photogrammetry, Cartography and Remote Sensing, 28, (2016)

4 I. Asi, Building and Environment, 42, (2007)

5 M. Wasilewska, W. Gardziejczyk, P Gierasimiuk, Transportation Research Procedia, 14, (2016)

6 Q. Liu, L. Kavanagh, A. Shalaby, B. Izevbekhai, Transportation Research Record: Journal of the Transportation Research Board, 2591, (2015)

7 A. Slimane, M. Khoudeir, J. Brochard, M. Do, Wear, 264, (2008)

8 V. Knyaz V, A. Chibunichev, The International Archives of the Photogrammetry, Remote Sensing and Spatial Information Sciences, XLI-B5, (2016)

9 A. Pożarycki , J. Fengier, M. Wyczałek , P. Skrzypczak, M. Wesołowski, K. Blacha, Road engineering, 3, (2017)

10 B. Persson, Journal of Physics: Condensed Matter, 18, (2006)

11 A. Ueckermann, D. Wang, M. Oeser, B. Steinauer, Journal of Traffic and Transportation Engineering, 2, (2015)

12 A. Ueckermann, D. Wang, M. Oeser, B. Steinauer, International Journal of Pavement Engineering, 16, (2015) 
13 M. Kanafi, A. Tuononen, Tribology International, 107, (2017)

14 P. Gierasimiuk, W. Gardziejczyk, Rzeszow University of Technology Research Notebooks, 59, (2012)

15 M. Kanafi, A. Kouosmanen, T. Pellinen, International Journal of Pavement Engineering, 16, (2015)

16 M. Słowik, M. Bartkowiak, Road engineering, 7-8, (2016) 